\title{
A interface currículo-educação em Ciências na Amazônia: narrativa de professores em formação continuada
}

The education-curriculum interface in Science in the Amazon: narrative of teachers in continuing education

\section{El interfaz currículo-educación en Ciencias en la Amazonia: narrativa de los docentes en la educación continua}

Simone Souza Silva, mestre em Educação e Ensino de Ciências na Amazônia pela Universidade do Estado do Amazonas e professora do curso de Pedagogia do Centro de Estudos Superiores de Parintins/ Universidade do Estado do Amazonas. Endereço: Rua Marechal Castelo Branco, $\mathrm{n}^{\circ} 1153$ - Bairro Francesa. CEP: 69151-480 - Parintins, AM. Telefone: (92) 9261-9777.E-mail: monesivapin@bol.com.br.

Amarildo Menezes Gonzaga, doutor em Educação / Desenvolvimento Curricular pela Universidad de Valladolid e professor do Programa de Pós-Graduação em Educação e Ensino de Ciências na Amazônia/ Escola Normal Superior/Universidade do Estado do Amazonas. Endereço: Rua Brigadeiro João Camarão, 39. Condomínio Solar dos Franceses. Torre Reno, apto. 103. CEP: 69040-080 - Manaus, AM.Telefone: (92) 9902-5910.E-mail: amarildo.gonzaga@yahoo. com.br.

Resumo

Investigação sobre a interface currículo-educação em Ciências e suas implicações para a educação e o ensino de ciências na Amazônia a partir da narrativa de um grupo de professores em um curso de mestrado acadêmico, do Programa de Pós-Graduação em Educação e Ensino de Ciências na Amazônia da UEA. Fundamentada em estudos realizados 
por autores como Goodson (2003), Delizoicov (2004), Cachapuz (2005), Moraes, Hachmann e Mancuso (2005), Silva (2007), Lopes (2007), Arroyo (2011), Demo (2010) e Chassot (2011). Percurso metodológico centrado na abordagem qualitativa do tipo narrativa, sustentado pelas técnicas de observação participante, entrevista narrativa, grupo focal e análise documental. Constatação de que a valorização da vivência e experiência de professores em formação continuada em Educação em Ciências a partir da pesquisa narrativa pode auxiliar processos de (re)pensar o currículo na Amazônia.

Palavras-chave: Currículo. Educação em Ciências.Formação Continuada.

\section{Abstract}

This study investigates the education-curriculum interface in Science and its implications for education and science teaching in the Amazon from the narrative of a group of teachers in the academic master ${ }^{-}$s course within the Graduate Program in Education and Science Teaching at UEA. It is based on studies conducted by authors such as Goodson (2003), Delizoicov (2004), Cachapuz (2005), Moraes, Hachmann and Mancuso (2005), Silva (2007), Lopes (2007), Arroyo (2011), Demo (2010), and Chassot (2011). The methodological route centered on a qualitative approach of narrative nature, supported by the techniques of participant observation, narrative interviews, focus groups and documentary analysis. The findings revealed that the valuation of experience and expertise in the continuing education of teachers in Science Education through narrative research can promote processes of (re)thinking the curriculum in the Amazon.

Keywords: Curriculum. Science Education. Continuing Education.

\section{Resumen}

Este artículo trata de investigar la interfaz currículo-educación de Ciencias y sus implicaciones para la educación y la enseñanza de 
Ciencias en la Amazonia desde la narrativa de un grupo de docentes de un máster académico del Programa de Posgrado de Educación y la Enseñanza de Ciencias en la Amazonía de la UEA. Basado en estudios realizados por autores como Goodson (2003), Delizoicov (2004), Cachapuz (2005), Moraes, Hachmann y Mancuso (2005), Silva (2007), Lopes (2007), Arroyo (2011), Demo (2010) y Chassot (2011). El enfoque metodológico se centra en el abordaje cualitativo del tipo narrativa, con el apoyo de las técnicas de observación participante, la entrevista narrativa, el grupo focal y el análisis documental. Se comprueba que valorizar la experiencia y los conocimientos de los docentes en la educación continua en la Educación en Ciencias desde la investigación narrativa puede ayudar en los procesos de (re) pensar el currículo en la Amazonia.

Palabras clave: Currículo. Educación en Ciencias. Educación Continua.

\section{Introdução: Educação em Ciências na Amazônia - contexto de sua instituição na Universidade do Estado do Amazonas}

O Amazonas é um estado localizado na Região Norte do Brasil. Possui a maior extensão territorial do País e uma população de 3,5 milhões de habitantes (IBGE, 2010). É constituído por 62 municípios, sendo banhado pelo Rio Amazonas e seus afluentes. Tem uma diversidade muito rica de fauna e flora, o que o torna diferente de outros estados brasileiros, devido as suas riquezas minerais e vegetais, ao volume de água potável etc. Tudo isso vem sendo explorado por grandes projetos e agronegócios, que visam ao enriquecimento de grupos econômicos, desconsiderando o homem amazônida.

Historicamente, a Região Norte, especificamente o Amazonas, por uma série de fatores, sempre teve dificuldades para fazer pesquisa e para divulgar os conhecimentos científicos produzidos. A distribuição de renda extremamente desigual entre as diversas regiões do País, a falta de incentivo para a permanência de pesquisadores na região e a falta de recursos para financiamento e divulgação das pesquisas realizadas podem ser enumeradas como fatores desfavoráveis. Durante muito tempo, a precária produção de conhecimentos sobre a Amazônia foi 
realizada por europeus, norte-americanos e, por último, brasileiros das regiões Sudeste e Sul, que acabaram por legitimar, por meio de seus registros, muitas vezes apressados, uma visão distorcida sobre a região amazônica (MEIRELLES FILHO, 2006).

A Região Norte apresenta carências na área de Educação em Ciências. Em particular, uma das maiores dificuldades reside na limitação de quadros profissionais qualificados para o ensino e para a pesquisa no contexto amazônico, o que requer sejam considerados elementos igualmente importantes, como a valorização social da profissão, os salários, as condições de trabalho, a infraestrutura das escolas, as formas de organização do trabalho escolar e a carreira, que devem fazer parte de uma política (de Estado e de governo) de apoio aos docentes (GATTI; BARRETO; ANDRÉ, 2011). Embora o conhecimento sobre o contexto amazônico já esteja sendo desvelado pelas universidades e instituições de ensino e pesquisas locais, sobretudo pelas universidades federais e estaduais de cada estado da Amazônia, como o Amazonas, Pará, Amapá, Acre, Rondônia, Roraima, Tocantins e Mato Grosso, elas não são suficientes para atender à demanda da população, que, em sua maioria, ainda não tem acesso ao ensino superior. Tal discussão coloca em xeque a necessidade de as universidades e instituições de pesquisa existentes no Amazonas tratarem de forma mais urgente as questões relacionadas à qualificação de recursos humanos para o ensino, a pesquisa e a extensão na Amazônia.

A Universidade do Estado do Amazonas (UEA) não se eximiu do papel de formadora de um "cidadão autêntico, pois seu papel mais substantivo vai muito além da formação do profissional, do técnico e do especialista (...) precisa ser (formadora) da consciência social que éa única sustentação de um projeto político minimamente equitativo, justo e emancipador" (SEVERINO, 2009, p. 6).

No entanto, ainda há uma grande carência de professores na área de Educação em Ciências para ministrar as disciplinas de Biologia, Química, Física e Matemática (UEA, 2011). A maioria dos professores que trabalha com essas disciplinas não é licenciada na área, consequentemente, ocorrem deficiências no processo de ensino 
e aprendizagem de crianças, jovens e adultos que estudam em escolas amazonenses. A situação se agrava quando se trata do ensino oferecido nas escolas ribeirinhas, nas quais faltam professores qualificados para o atendimento das demandas de uma realidade reprimida. Essa situação infringe os dispositivos legais previstos na Lei de Diretrizes e Bases da Educação - LDB/1996, cujo art. 61 preconiza que a formação de professores para a educação básica deve ter como fundamento: "a presença de sólida formação básica, que propicie o conhecimento dos conhecimentos científicos e sociais de suas competências de trabalho" (BRASIL, 1996).

Esse quadro é decorrente do grande fosso e desequilíbrio regional na distribuição de Instituições de Ensino Superior (IES) pelas regiões do País. De acordo com Ristoff (2008), ocorre uma verdadeira sudestificação da educação, pois as regiões Sul e Sudeste acumulam mais da metade das IES, dos cursos de graduação e das matrículas do Brasil.

De acordo com o Censo do IBGE 2000 a 2010, o percentual de pessoas com ensino superior completo no Sudeste subiu de $6 \%$ para $10 \%$, enquanto na Região Norte houve aumento de 1,9\% para 4,7\% e, no Nordeste, de 2,3\% para 4,7\%. As estatísticas do IBGE (2010) comprovam avanços na educação, mas a desigualdade continua quanto ao número de pessoas com nível superior entre as diversas regiões do País. A maioria da população amazonense ainda está longe de ter acesso universalizado ao ensino superior.

Como forma de redução das desigualdades na oferta de programas de pós-graduação na região amazônica, foi aprovada, em 2009, a Rede Amazônica de Educação em Ciências e Matemática (Reamec). A rede congrega doutores da área dispersos na região amazônica, cuja densidade não permitiria a criação de cursos de doutores em outros estados, além do já existente no Pará (CAPES, 2010).

O Plano Nacional de Educação (PNE 2011-2020) prevê como desafios prioritários ao desenvolvimento do País o acesso e a permanência na educação básica e a expansão da oferta de ensino superior. Na mesma direção, o encontro de pró-reitores de Pesquisa e Pós-Graduação das Instituições de Ensino Superior e de Pesquisa da 
Região Norte (IES/IP-N)' refletiu o compromisso de definições políticas indispensáveis à inclusão da Região Norte nos projetos nacionais de desenvolvimento da pesquisa científica e da pós graduação brasileira para a próxima década. Destaca-se como um dos maiores desafios para o desenvolvimento científico e tecnológico: a superação das assimetrias regionais e políticas adicionais para a formação de recursos humanos para a pesquisa científica e tecnológica, a atração e fixação de doutores e a expansão da pesquisa e da pós-graduação.

As discussões apresentadas apontam para a necessidade de investimentos na formação inicial e continuada de professores, rumo ao desenvolvimento articulado, identitário e profissional para essa finalidade. Severino e Pimenta (2011, p. 12) não ignoram que "esse desafio precisa ser prioritariamente enfrentado pelas políticas de governo e que os professores são profissionais essenciais no processo de transformação da realidade". Para isso, o professor precisa "ampliar sua consciência sobre a própria prática, a de sala de aula e a da escola como um todo, o que pressupõe conhecimentos teóricos e críticos sobre a realidade" do contexto amazônico (Ibidem, p. 13).

O curso de mestrado acadêmico da UEA surgiu como possibilidade de ampliar o universo de acesso à formação para quadros de instituições da educação básica e do ensino superior, contribuir para o ensino, a pesquisa e a extensão e, ao mesmo tempo, reduzir as grandes diferenças de formação em nível de pós-graduação existentes na Região Norte e no País.

Fórum Nacional de PróReitores de Pesquisa e Pós-Graduação das IES Brasileiras (Foprop) Região Norte. Carta de Boa Vista. Boa Vista - Roraima, 11 de maio de 2011.

A UEA é uma instituição estratégica para o desenvolvimento da Região Norte. Instituída em 2001, visa, entre outros objetivos, promover a educação, o conhecimento científico, particularmente sobre a Amazônia, conjuntamente com os valores éticos capazes de integrar o homem amazônida à sociedade e aprimorar a qualidade dos recursos humanos existentes na região.Em dez anos de existência, formou mais de 20 mil professores, entre eles 7.150 graduados no curso normal superior no Programa de Formação de Professores (Proformar), projeto vencedor do prêmio Objetivos do Milênio e apontado pela Organização das Nações Unidas para a Educação, a Ciência e a Cultura (UNESCO) como modelo para outros países (UEA, 2011). 
A UEA possui 43 cursos de graduação nas diversas áreas. No que trata da formação de professores, destacamos aqui as licenciaturas ligadas à área de Ensino de Ciências: Física, Química, Biologia, Matemática e Pedagogia (séries iniciais) na modalidade regular nos diferentes polos² da instituição em todo o Estado do Amazonas.

Desde 2002, a UEA desenvolve atividades na pós-graduação lato sensue stricto sensue, em 2011, contava com sete cursos de mestrado e dois doutorados. Destacamos, no stricto sensu, o Programa de PósGraduação em Educação e Ensino de Ciências na Amazônia.

O curso de mestrado acadêmico em Educação em Ciências é novo na UEA e resulta dos desdobramentos da interface ensinopesquisa a partir do processo de consolidação do Programa de Mestrado Profissionalizante em Ensino de Ciências na Amazônia. Credenciado pela Coordenação de Aperfeiçoamento de Pessoal de Nível Superior (Capes) no ano de 2006, houve quatro entradas, sendo que a primeira foi concluída no início de 2009 e a última no início de 2012.

Em sua trajetória, o Programa de Mestrado Profissionalizante formou 72 profissionais para o ensino de Ciências no Amazonas. Contudo, embora o mestrado fosse profissional, o perfil do grupo de pesquisa e colegiado vinculado a ele era acadêmico. Decorrente das avaliações realizadas pelo grupo de pesquisadores que o conduziam, foi sugerida a mudança de mestrado profissional para mestrado acadêmico. Tais avaliações sugeriam a necessidade de as atenções se voltarem à pesquisa e à formação do pesquisador, cujo foco priorizasse não somente a geração de processos e produtos (MOREIRA, 2007, p. 37) para a otimização do ensino 3 , mas também o redimensionamento da Ciência para além do ensino, adotando como eixo mediador a construção de uma cidadania que, efetivamente, seja para a vida. Assim, o Mestrado Profissional em Ensino de Ciências na Amazônia mudou para Mestrado Acadêmico em Educação e Ensino de Ciências.

A ampliação do olhar da área de Educação em Ciências para além do ensino no contexto amazônico implica promover a educação científica, que, de acordo com Gonzaga (2011)4, envolve as dimensões ontológica, epistemológica e metodológica do professor pesquisador.

2 Centros de Estudos Superiores: Itacoatiara, Lábrea, Parintins, São Gabriel da Cachoeira, Tabatinga e Tefé. ${ }^{3}$ No mestrado profissional, devem ser construídos mais produtos educacionais (manuais, aplicativos, vídeos, ambientes virtuais etc.) do que produção, publicação e divulgação de conhecimentos necessários para a legitimação da área de ensino de Ciências.

4 Proferido na conferência de abertura "A Educação Científica na Formação Continuada de Professores no CESP-UEA: o caso do Nepecip", no Seminário "Os percursos investigativos em educação em ciências da Amazônia no polo de Parintins", realizado no auditório do Centro de Estudos Superiores de Parintins em 21 de outubro de 2011 
O mestrado acadêmico, portanto, possibilita aos professores retroalimentarem seu trabalho pedagógico a partir da educação científica.Visa a que suas ações estimulem o aluno a partir de redes investigativas e considera os requisitos, as necessidades e os interesses advindos da posição geográfica e do contexto sociopolítico atual da região amazônica.Em consonância com os pressupostos evidenciados, sua proposta curricular tem como foco a educação em Ciências na Amazônia, com base nas exigências do século XXI. Deve possibilitar a produção de conhecimentos, tendo em vista a assunção de um compromisso ético e político capaz de contribuir com o povo amazônida, ainda marginalizado dos processos educativos.

O mestrado atende a uma demanda reprimida existente na Região Norte entre estudantes egressos dos cursos de graduação, como perspectiva de responder aos desafios de propor metodologias e tecnologias alternativas que possam apontar saídas para os problemas de ensino ali enfrentados. Uma de suas propostas é superar limitações teórico-epistemológicas e metodológicas diagnosticadas na educação básica e superior, a partir de alternativas possíveis de consolidar estados de consciência pautados na formação de uma cidadania cujo princípio norteador seja a interface Educação-Ciência.

Propõe, sobretudo, subsidiar pesquisas para a produção de conhecimentos na área e na compreensão do papel das ciências e da escola na formação para a cidadania no ambiente amazônico. Concentra duas linhas de pesquisa, a saber: Educação em Ciências, Cognição e Currículo e Educação em Ciências e Divulgação Científica e Espaços não Formais.

As definições dessas linhas de investigação foram arquitetadas na perspectiva de contribuir para a superação dos desafios propostos para a alteração da realidade amazônica, como: formar docentes pesquisadores, em nível de mestre, dando ênfase às questões da Amazônia; fortalecer, a partir do ensino e da pesquisa, de modo a consolidar, grupos de pesquisadores aptos a construir conhecimentos na área; e contribuir efetivamente para a formação dos professores, em especial os docentes que atuam nas licenciaturas em Química, Física, 
Biologia e Matemática, e docentes que atuam na área em cursos de Pedagogia, concorrendo, assim, para mudanças de patamar no que se refere à qualidade do ensino e da pesquisa na região amazônica.

Os objetivos almejados pelo curso de mestrado caminham para dar suporte a um projeto de transformação da realidade educativa e social no contexto amazônico. Assim, compartilhamos com o pensamento de Freire (1996, p. 12) quando enfatiza: "se a educação não pode tudo, alguma coisa fundamental a educação pode. Se a educação não é a chave das transformações sociais, não é também simplesmente reprodutora da ideologia dominante". A educação sozinha não pode transformar a realidade regional amazônica, porém, sem ela, poucas transformações serão possíveis. Esse desafio requer que se refaçam caminhos em busca de respostas que se materializem em atitudes, sobretudo por parte do estado, na implementação de políticas públicas para possibilitar o desenvolvimento regional.

De acordo com o regimento interno do curso, o mestre em Educação em Ciências na Amazônia precisa ter consciência dos limites e das possibilidades do próprio processo investigativo que pode contribuir para um projeto de transformação da sociedade.

O mestrado acadêmico está atrelado à Rede Amazônica de Educação em Ciências e Matemática (Reamec), em nível de doutorado, subdividido em três grandes polos: Mato Grosso, Pará e Amazonas, que concentra os subpolos Roraima e Acre. O polo do Amazonas é composto por instituições como o Instituto Federal de Educação, Ciência e Tecnologia do Amazonas (Ifam), a Universidade Federal do Amazonas (Ufam), a Universidade Nilton Lins e a UEA, inseridas nos municípios de Manaus, Parintins, Tefé e Tabatinga.

Na UEA, a Reamec é sustentada pelo Programa de Educação em Ciências e Matemática da Amazônia, por intermédio do doutorado em Educação em Ciências e Matemática, mestrado acadêmico em Educação em Ciências na Amazônia, do qual também faz parte o Núcleo de Estudos e Pesquisa em Educação Científica de Parintins (Nepecip), criado para contribuir na tessitura da respectiva rede. Sua consolidação representa 
a possibilidade de uma contribuição mais autêntica da educação em Ciência na formação de cidadãos cientificamente alfabetizados que se queiram capazes de alterar a realidade de nosso lócus de atuação acadêmico, profissional e social, enfim, de nosso País.

\section{A Educação em Ciências em Parintins: o Nepecip como estratégia de autoria e produção científica no Baixo Amazonas}

A cidade de Parintins está localizada à margem direita do Rio Amazonas. Possui uma população de 102 mil habitantes (IBGE, 2010). Sua sede está assentada sobre a Ilha Tupinambarana, distante da capital do estado - Manaus - cerca de 369 quilômetros em linha reta e 420 quilômetros por via fluvial. Para chegar a Parintins, pode-se utilizar transporte aéreo ou fluvial.

Parintins é mundialmente conhecida pelo Festival Folclórico que realiza no mês de junho, quando ocorre uma das maiores expressões artísticas locais, com a apresentação dos bois-bumbás Garantido e Caprichoso no Bumbódromo, arena com capacidade para 20 mil expectadores. O Festival Folclórico de Parintins recebe visitantes de todo o mundo atraídos pela beleza e exuberância da cultura amazônica, celebra a identidade regional cabocla e contribui para o fortalecimento da cultura brasileira (SAUNIER, 2003).

Desde o ano de 2000, a cidade vem se destacando na área da educação, em grande parte motivada pela instalação de instituições de ensino superior, como o Centro de Estudos Superiores de Parintins (Cesp/ UEA), em 2001, o Instituto de Ciências Sociais, Educação e Zootecnia da Universidade Federal do Amazonas (ICSEZ/Ufam), em 2007, e o Ifam, em 2010, que trabalham para fortalecer a educação básica em Parintins e

${ }^{5}$ Barreirinha, Boa Vista do Ramos, Maués, Nhamundá, São Sebastião do Uatumã e Urucará.

${ }^{6}$ Faro, Terra Santa, Juruti, Oriximiná, Óbidos e Santarém. nos municípios do Polo do Baixo Amazonas 5 e a oeste do Pará6.

O Cesp/UEA, criado em agosto de 2001, com oito cursos de graduação, no ano de 2010, já havia formado 1.249 alunos nos cursos oferecidos. Durante os dez anos de trajetória, o Cesp tem contribuído 
para a prática da pesquisa, que tem se tornado um dos caminhos para a análise crítica do contexto da realidade local.

No ano de 2010, a UEA ofertou 15 vagas do curso de mestrado acadêmico em Educação e Ensino de Ciências para professores do polo Parintins. Esse grupo de professores havia ingressado na carreira acadêmica no Cesp/UEA em 2009, via concurso público; entre eles, dez foram sujeitos deste estudo por meio da pesquisa narrativa. 0 registro da pesquisa foi realizado por meio de gravações de voz, que, depois, foram transcritas e textualizadas (MEIHY; HOLANDA, 2007), tendo o devido cuidado de preservar o conteúdo das gravações. A opção de trabalhar com as narrativas justifica-se pelo entendimento de que a compreensão pode avançar no caminho da transformação (SANDíN ESTEBAN, 2010).

A metodologia centrada em narrativas pessoais de professores repercute um espaço significativo na formação docente, porque permite refletir sobre a prática pessoal, profissional e social e suas transformações no trabalho docente, por meio da reflexão. Prado e Soligo (2007, p. 54) afirmam que: “A narrativa é um excelente veículo para tornar público o que fazemos. Isso é fundamental porque a memória dos profissionais é pouco valorizada em nossa cultura”. Assim, “podemos produzir no outro a compreensão daquilo que estamos fazendo e do que pensamos sobre o que fazemos" (Ibidem).

Delizoicov (2004) faz menção ao movimento que sai do ensino das Ciências (Física, Química, Biologia) para o ensino de ciências humanas. No caso dos sujeitos desse estudo, professores mestrandos que compõem o Nepecip, é evidente a saída das múltiplas áreas de conhecimento ${ }^{8}$ para a área de Educação em Ciências.

Os professores mestrandos advêm de áreas de conhecimentos diferentes, e, por meio de um olhar multidisciplinar - característico da área de Educação em Ciências $^{9}$-, realizam pesquisas relacionadas à realidade do município de Parintins, a partir de quatro focos de ação: estudo, discussão, produto e publicação, visando construir a identidade de professor que forma e educa cientificamente outras pessoas.
8 A reflexão é um processo de conhecer como conhecemos, um ato de voltar a nós mesmos, a única oportunidade que temos de descobrir nossas cegueiras e conhecer que as certezas e os conhecimentos dos outros são, respectivamente, tão aflitivos e tão tênues quanto os nossos (MATURANA VARELA, 2001, p. 29-30).

8 Os mestrandos são das áreas de Letras, Pedagogia, Filosofia, História, Geografia Matemática e Física.

9 A área de Educação em Ciências busca articuladores de diversas associações profissionais, constituindo uma área de conhecimento multidisciplinar. 
A inserção da equipe multidisciplinar na área de Educação em Ciências constitui um desafio para todos nós: construir, a partir da área de Educação em Ciência, uma identidade, legitimando paradigmas emergentes e tidos, por algumas comunidades científicas, como marginais. Isso exigia de todos "uma responsabilidade de ressignificar nossa identidade para construirmos/alterarmos a realidade, embasados na ciência, em uma epistemologia da educação" (GHEDIN ${ }^{10}$, 2010, aula inaugural).

Tornou-se imprescindivel o domínio de conhecimentos e conceitos predominantes na área de Educação em Ciência, assim como a aquisição de informações sobre quais trabalhos, quais eventos, quais periódicos e quais livros poderiam ser os meios de divulgação dessa área de conhecimento que se apresentava como um princípio básico de inserção nessa realidade. Conhecê-la e familiarizar-se com ela era primordial. A partir disso, ressignificar nosso olhar para a realidade amazônica era algo que nos movia. Nas palavras de Ghedin (aula inaugural, 2010): “Estamos em um novo território epistemológico. É um movimento necessário pelo qual devemos passar. Esse movimento nos direciona a uma ponte que implica rever nosso papel para construirmos uma nova identidade".

A autoria da produção do conhecimento seria condição necessária para a formação identitária do docente pesquisador. Evidenciava-se aí a necessidade de compreender as epistemologias para entender o que estava sendo proposto e o que nos propúnhamos a fazer para dar sentido ao adjetivo professor pesquisador. Precisaríamos assumir tacitamente um compromisso moral com o curso de mestrado acadêmico.

${ }_{10}$ Na época, coordenador do Polo Amazonas da Rede Amazônica de Ensino de Ciências - Reamec.

A busca pela condição de autoria e autonomia intelectual deveria ser traçada a partir da compreensão dos limites e das possibilidades dos integrantes do Nepecip. Esse processo precisaria ser bem compreendido pelos professores em formação, pois o fato de estarmos adentrando um novo campo do conhecimento, uma nova cultura (o mestrado em Educação em Ensino de Ciências) aponta "para as potencialidades que podem ser abertas a partir desse novo fazer ciência na região amazônica que está no respeito e diálogo entre os diferentes saberes. Seria uma 
ciência amazônica, realizada a partir das considerações das riquezas culturais aqui existentes", como enfatizou o professor mestrando 1.

O processo formativo no mestrado acadêmico significou um trajeto de transformação em que as aprendizagens novas exigiram "desfazer-se de hábitos mais ou menos antigos, dos quais tomamos consciência de diferentes maneiras, como se fossem freios" (JOSSO, 2008, p. 19). Trata-se de processo complexo, e "a maioria de nós tem dificuldade de lidar com as contradições, pois nos formamos no postulado de verdades preestabelecidas e das certezas que a vida, como sabemos, não nos oferece" (MORAES; HACKMANN; MANCUSO, 2005, p. 33).

As atividades realizadas ${ }^{11}$ contribuíram para superar as dificuldades, possibilitando uma consistência teórica, o que pode ser evidenciado a partir de trechos do que foi narrado pelos professores mestrandos quando assim se posicionaram: "Senti dificuldades na realização das disciplinas. As leituras dos textos são complexas. Formamos um grupo de estudo para superar as dificuldades" (professor mestrando 3).0 professor mestrando 4, ao se posicionar a respeito desse fato, declarou: "Primeiramente fiquei empolgado em relação ao mestrado, mas depois fiquei confuso. Não conseguia me perceber no processo. A partir das disciplinas já consigo ver a realidade de outra forma: a dimensão do ensino, da educação científica, da alfabetização científica, ou seja, certos conceitos que antes não conseguia perceber".

As narrativas dos professores mestrandos revelam um momento de crise intelectual, o que exigiu "a superação dos obstáculos epistemológicos advindos do conhecimento comum" (LOPES, 2007, p. 64). Lopes (2007, p. 53) salienta que: “aprender ciências implica aprender conceitos que constrangem e colocam em crise conceitos da experiência comum”. O autor esclarece que o acesso à informação não garante conhecimento. $\mathrm{O}$ que garante é a análise, a reflexão, a produção a partir de sua reelaboração.

Daí a materialização do Nepecip ganhou importância fundamental, pois, de acordo com o professor mestrando 5, “os membros

${ }^{11}$ Estudo individual e coletivo, reuniões avaliativas, rodada de leitura e discussão de textos, painel integrado, seminário, mapas conceituais, fichamentos, resenhas, artigos, etc. 
do Nepecip, na maioria das disciplinas, se reuniram para estudar as obras enviadas pelos professores. [...] a partir dessas ações conseguimos êxito nas disciplinas, na prova de língua estrangeira e nas primeiras produções e publicações em diversos eventos”.

Um olhar atento à forma como a proposta do curso foi pensada e como o processo foi conduzido, principalmente a postura assumida por nossos mestres de "nos permitir errar, de não tentar nos enganar com a ciência fácil” (BACHELARD, 1972, apud LOPES, 2007, p. 70), foi o diferencial para o rompimento dos primeiros erros. Para Bachelard (1947, apud LOPES, 2007, p. 72), "quanto mais difícil é uma tarefa, mais ela é educadora”. Defende ele que "o trabalho de superar tais dificuldades deve ser permanente, nunca restrito ao período escolar, sempre mantendo viva a chama do processo de contradizer conhecimentos anteriores e estabelecer uma nova cultura”.

A legitimação de uma cultura científica, como a instituída por meio do Nepecip, dependeria da aceitação da comunidade científica. Na condição de professores mestrandos, em um estágio ainda tímido, mas um pouco mais cientes do papel do fazer ciência na Amazônia, lançamonos ao desafio de tornar públicos os conhecimentos construídos no núcleo. A participação em eventos poderia fortalecer a condição de autoria, e os conhecimentos produzidos seriam questionados, negados ou validados, como a ciência exige.

Uma das primeiras ações dos integrantes do Nepecip foi construir projetos de pesquisa depois aprovados pela Fapeam. Foram elaborados ainda projetos de extensão para a realização de eventos científicos no Cesp/UEA, que foram aprovados pela Pró-Reitoria de Extensão e Assuntos Comunitários (PROEXT) da UEA.

O evento / Ciclo de Palestras teve a finalidade de socializar/ divulgar os projetos de pesquisa produzidos pelos membros do núcleo, visando abrir espaço ao debate e buscar um ponto de convergência e diálogo entre os interessados em discutir a educação em Ciências na Amazônia. Foi uma experiência válida por socializar os projetos de pesquisa fora do ambiente do grupo e revelar a consistência teórica na apresentação. A experiência adquirida na organização desse primeiro 
evento nos fez, paulatinamente, superar as dificuldades sentidas no processo, como insegurança, medo de não sermos compreendidos ou mesmo de não atendermos às expectativas do público que ali estava.

O segundo evento realizado foi o Seminário Os Percursos Investigativos em Educação em Ciências da Amazônia no Polo de Parintins. Teve como objetivos comunicar os resultados parciais das pesquisas realizadas e promover o encontro entre pesquisadores e acadêmicos de diferentes instituições de ensino superior de Parintins, tendo em vista a necessidade de práticas pedagógicas mais realistas no contexto do Baixo Amazonas.

O terceiro evento, o Simpósio Investigação em Educação em Ciências no Polo Parintins, teve como objetivo socializar os resultados finais das pesquisas realizadas no âmbito da educação em Ciências Nepecip - Polo Parintins. Para a professora mestranda 2, a realização do Simpósio "mostrou que, se você estabelecer uma cultura científica na universidade como prática constante, o público acadêmico e a sociedade organizada em geral e outras instituições começam a aderir a essa prática. Assim, o simpósio foi sucesso de público, participação e qualidade nos trabalhos apresentados".

Timidamente, a partir da participação na organização dos três eventos realizados, começamos a romper com visões distorcidas de ciência, especificamente a de que o conhecimento produzido sobre a educação em Ciências no contexto amazônico está distante das discussões produzidas em âmbito nacional.

Trabalhos em eventos científicos com resultados parciais de pesquisas em andamento, em geral, possuem chances mínimas de aprovação, ainda mais em se tratando de eventos importantes para a área de educação, como o Encontro de Pesquisadores do Norte e Nordeste (EPENN) e o Encontro Nacional de Pesquisa em Educação em Ciências (Enpec). Foi em relação a esse desafio que fomos orientados a encaminhar artigos com resultados de pesquisa parciais no formato de pôster.

Após cursarmos as disciplinas propostas no mestrado, o Nepecip já não estava tão coeso; alguns optaram por um caminho individual, 
“talvez pelo tema escolhido, talvez por não terem conseguido ampliar seu espaço de trocas, ou - quem sabe - por viverem um momento em que há necessidade dos encontros com suas próprias vozes" (MORAES; HACKMANN; MANCUSO, 2005, p.37), ou mesmo por estarem ocupados com questões de seu fazer docente, pois durante todo o curso tivemos que conciliar o mestrado com as atividades profissionais da docência.

Outros, ao contrário, preferiram trilhar um caminho coletivo, estar junto de seus pares, partilhar experiências, em uma relação dialógica quando um lia o texto do outro, sugeria, com respeito e cumplicidade, o que, particularmente, considerava ser mais produtivo. 0 estar junto nos fortalecia, motivava, criava expectativas e acabou nos marcando de forma distinta, sendo o diferencial na aprovação dos trabalhos enviados aos eventos, como indica a professora mestranda 6: "“...] as trocas de experiência com os colegas me têm dado algumas orientações a respeito do meu trabalho. Claro que preciso ainda crescer bastante nessa questão de produção, mas, revendo o que já produzi, vejo que já consegui avançar bastante”.

O primeiro evento para o qual submetemos nossos trabalhos foi o XX EPENN, um encontro bianual vinculado à Associação Nacional de Pós Graduação (Anped), cujo objetivo é o fortalecimento dos programas de pós-graduação, da pesquisa e da produção intelectual voltada para a área educacional. 0 momento da decisão que antecede o envio de trabalhos corresponde a um tempo intelectual duvidoso no mestrado acadêmico e pode ter influenciado no momento da decisão da inscrição dos trabalhos.

Como fomos orientados a enviar nossos trabalhos em forma de pôster - e mesmo não tendo experiência de contato com o ambiente de discussão em âmbito nacional e com o pouco tempo de estudo do tema -, alguns de nós arriscamos submetê-los como comunicação oral. Enviados os trabalhos, aguardávamos ansiosos os resultados. Perguntávamo-nos: receberíamos a carta de aceite? Como reagiríamos se o trabalho não fosse aprovado?

As cartas de aceite foram chegando aos poucos e, na medida em que chegavam, uma explosão de alegria contagiava cada um de nós. Essa situação se repetiu inúmeras vezes e em espaços de tempo diferentes, 
até que todos tivessem recebido a aprovação dos trabalhos enviados. 0 fato de todos termos os trabalhos aprovados no XXEPENN nos marcou sobremaneira, como enfatizou o professor mestrando 1: "Pudemos olhar não somente para nosso tema com outros olhos/perspectivas, mas perceber a grande riqueza de pesquisas que o grupo de Parintins possui".

O aceite dos trabalhos representou para nós a validação dos conhecimentos produzidos pelo Nepecip, uma vez que os trabalhos foram submetidos à crítica de diferentes interlocutores intelectuais, o que contribuiu para que recebessem versões melhoradas que se configurariam posteriormente em capítulos de dissertações.

Outro evento de que participamos foi o IV Seminário de Ensino em Ciências na Amazônia (Secam), uma iniciativa de professores e estudantes do Programa de Pós-Graduação em Ciências da Amazônia, da UEA. Foi significativo para o Nepecip, dada a aprovação de 23 trabalhos de mestrandos e acadêmicos do Cesp/UEA. Durante o IV Secam, houve participação dos mestrandos nos processos de discussão, reflexão e interação entre professores e alunos pesquisadores da área das ciências da região amazônica. Tais discussões e reflexões tinham como foco a melhoria do ensino de ciências no contexto amazônico.

O último evento de que participamos foi o VIII Enpec, ocorrido em Campinas/SP simultaneamente ao / Congreso Iberoamericano de Investigación en Enseñanza de las Ciencias (CIEC). Um evento bienal promovido pela Associação Brasileira de Pesquisa em Educação em Ciências (Abrapec).

Desde que iniciamos o mestrado, o Enpec foi o evento mais esperado. A aprovação de algum trabalho seria a oportunidade de participarmos das discussões dos principais pesquisadores representantes da área de Educação em Ciências no Brasil, na América Latina e nos países ibéricos, que só conhecíamos por meio de leituras de seus trabalhos. Na ocasião conseguimos o aceite de sete trabalhos, sendo seis em forma de comunicação oral e um em forma de pôster. Isso revela que as produções dos integrantes do Nepecip não estão distantes 
das discussões produzidas no contexto nacional sobre a educação em Ciências, como temíamos. Ao contrário, como refletiu o professor mestrando 1: "Nosso grupo de pesquisa teceu inúmeras discussões nos dias de evento. [...] Senti-me realizado em participar de tais discussões”.

Tal fato indica que e como podemos participar de forma mais expressiva do processo que se abre para a construção de um novo tipo de educação no País. Uma educação que pode se fazer não mais somente do centro para as periferias, mas, ao contrário, das periferias, como é o caso do Baixo Amazonas, para o centro. Para Martins ${ }^{12}$ (2011, p. 6), "os trabalhos apresentados neste evento reforçam este compromisso, consolidam esta identidade e expressam nossas contribuições para uma educação em ciências de qualidade".

A participação nesses eventos nos ajudou a refletir a respeito da responsabilidade que temos como protagonistas dessa história de (re) construção da educação científica no currículo dos futuros mestres em educação em Ciências ao atuarmos em ambientes socioculturais. Destacamos aqui a ressignificação da proposta curricular no processo de formação, como diferencial para a superação dos desafios.Como afirmou o professor mestrando 7: “Não somos mais os mesmos neste momento aqui [momento final do curso], os conhecimentos adquiridos com certeza nos transformaram, nos fizeram redimensionar os pensamentos".

\section{A interface currículo-educação em Ciências na perspectiva de integrantes do Nepecip}

O termo interface pode ser considerado como área em que dois pontos interagem. Gostaríamos de refletir acerca da conexão entre currículo e educação em Ciência a partir de narrativas de professores em formação continuada no mestrado acadêmico em Educação em Ciências na Amazônia.

${ }^{12} \mathrm{Na}$ época, presidente da Associação Brasileira de Pesquisa em Educação em Ciências (Abrapec).
Goodson (2003), Pacheco (2005), Silva (2007), Lopes (2007) e Arroyo (2011) são alguns dos importantes autores que discutem currículo e que servem como ponto de ancoragem para a compreensão 
de currículo e como isso impacta na ação/reflexão/ação de professores mestrandos em formação ao fazer e ensinar Ciências na Amazônia.

Pacheco (2005), na condição de teórico que discute questões curriculares, compreende que a definição do termo currículo não se torna uma tarefa prioritária, pois jamais uma definição contribuirá para a existência de um pensamento comum sobre uma realidade, construída na multiplicidade, de práticas concorrentes para uma mesma finalidade: a educação de sujeitos em razão de percursos de aprendizagem.

Essa questão é também discutida por Silva (2007), quando nos alerta que uma definição não nos revela o que é currículo, e, sim, o que determinada teoria pensa o que o currículo é. Acrescenta ainda que talvez mais importante do que a busca para defini-lo seja a de saber que questões uma teoria do currículo ou um discurso curricular busca responder. A questão central para qualquer teoria do currículo é saber qual conhecimento deve ser ensinado.

Não é nossa pretensão aqui exaurir o campo de definições conceituais; elas são úteis na medida em que contribuem para o entendimento e as reflexões da temática em tela, para refletirmos como temos compreendido ou vivido o currículo. Goodson (2003) considera que a dicotomia entre o currículo adotado por escrito e o currículo ativo, tal como é vivenciado e posto em prática, é complexa e inevitável.

A partir dessa compreensão, precisaríamos saber que sentido dar ao currículo do curso de mestrado acadêmico. Um desafio importante a ser enfrentado a partir desse processo de compreensão se referia à tomada de decisões quanto às questões técnico-científicas ou sociocientíficas. A esse respeito, Azevedo (2005) ressalta que a tomada de decisões é uma importante capacidade que pode ser educada e deve ser um dos objetivos de muitos currículos de ciências, formulado de diversas maneiras com a finalidade de levar os alunos a participarem, responsavelmente, na tomada das decisões que envolvem a sociedade.

Trata-se "de selecionar a informação pertinente e necessária para fundamentar raciocínio e decisões" (ZANCAN, 2000, p. 6). Para esse autor, "a mudança básica significa não se limitar a memorizar 
um conjunto desconexo de fatos, mas, sim, estruturar um arcabouço relevante para análise de conceitos básicos para a compreensão da ciência" (Ibidem).

Para o mestrando 7, o currículo "é um instrumento vivo a serviço da possibilidade necessária para a melhoria das condições de vida dos envolvidos no processo educacional". A forma como compreendem e vivenciam o currículo pode ser o grande diferencial em seu processo de formação, pois o currículo pode ser um instrumento utilizado tanto para reprimir e alienar quanto para libertar e possibilitar uma visão crítica e abrangente da realidade. É preciso que nos identifiquemos no processo e, a partir dessa identificação, tentemos ressignificar o que fazemos. “Afinal, um currículo busca precisamente modificar as pessoas que vão 'seguir' aquele currículo"' (SILVA, 2007).

O currículo do mestrado acadêmico precisa ser retroalimentado por uma educação científica. Cachapuz (2005), Demo (2010), Chassot (2011), entre outros estudiosos, têm discutido a respeito da importância da educação científica na sociedade atual.

Demo (2010, p. 15) afirma que a educação científica é vista como uma das habilidades do século XXI, por ser este século marcado pela "sociedade intensiva de conhecimento". Argumenta em favor da educação científica, em tom crítico ao positivismo. Para o referido autor, "a educação científica só poderia progredir mais visivelmente se cuidássemos bem melhor da formação docente: se o docente só dá aula, sem produção própria, não podemos superar o instrucionismo dominante na escola e na universidade" (Ibidem).

Na mesma direção, Cachapuz (2005, p.19) tem discutido que "a educação científica converteu-se, na opinião de especialistas, numa exigência urgente, num fator essencial do desenvolvimento das pessoas e dos povos, também a curto prazo" (grifo do autor).

A declaração da UNESCO na Conferência Mundial sobre a Ciência para o século XXI confirma tais anseios sobre esse tipo de educação, na medida em que preconiza que, "para que um país esteja em condições 
de satisfazer as necessidades fundamentais de sua população, o ensino das ciências e a tecnologia é um imperativo estratégico" (UNESCO, 2013, p. 50).

Como se vê, as discussões em torno da necessidade de educação científica têm ocupado lugar de destaque nas pautas de congressos, encontros e publicações na busca de entender como esse mecanismo interfere na vida das pessoas e da sociedade, principalmente no que diz respeito à exigência de uma alfabetização científica e tecnológica para todos.

Na visão da professora mestranda 8, "o mestrado oferece a oportunidade de desenvolver pesquisa e, ao mesmo tempo, dar significado à educação científica. Estou ciente de que contribuirá com minha prática docente e com a formação de outros professores os quais auxilio em seu processo de formação".

A proposta de formação do mestrado se configurou como um processo natural, contínuo e necessário para a melhoria da formação identitária e profissional docente em educação e ensino de ciências no contexto amazônico (SEVERINO; PIMENTA, 2011). Isso é evidenciado nas palavras do mestrando 1, que se percebe como "um sujeito que aprende cada vez mais a importância de sua função dentro do processo educacional no Baixo Amazonas, ajudando na construção de uma ciência mais voltada para a realidade amazônica”.

As narrativas, de modo geral, revelam que o currículo do mestrado possibilitou-nos perceber que a educação científica é um processo de formação importante e necessário que deve permear a formação constantemente. Acreditamos que o processo formativo no mestrado é uma etapa que possibilita compreender mais e melhor a educação científica, pois, por meio desse processo, os professores em formação compreendem a pesquisa, a ciência, o processo investigativo, enfim, como um dos caminhos para a transformação da realidade a que pertencem. 


\section{Considerações finais}

Neste estudo, buscamos a compreensão da interface currículo -educação em Ciências e suas implicações para a educação e o ensino de Ciências na Amazônia, a partir da narrativa de dez professores mestrandos do curso de mestrado acadêmico em Educação e Ensino de Ciências.

Constatamos o quanto, na prática, é importante a narrativa de vivências e experiências de professores, por proporcionar um (re) pensar sobre o processo de formação continuada e sua ligação com a própria prática, inclusive na condição do que nos moverá nessa trajetória, pois, por intermédio desse processo, os professores em formação compreendem a pesquisa, a ciência e o processo investigativo como um dos caminhos para a transformação da realidade na qual estão inseridos.

Ao relacionarmos a necessidade de educação científica para a (re) construção do currículo no mestrado acadêmico, chamamos a atenção para o fato de que esse é um processo que exige que cada sujeito se sinta integrante e igualmente importante no processo de (re)construção da rede de saberes locais a respeito do Ensino de Ciências na Amazônia, o que não se esgota com a conclusão do curso nem nesta discussão. Reconhecemos que a educação precisa de esforços conjuntos, sobretudo de implementação de políticas públicas prioritárias para a formação identitária e profissional docente, além de ser contínua e retroalimentada pela educação científica.

Por fim, temos clareza de que é possível sermos protagonistas como sujeitos que investigam e que se permitem ser investigados, para efeito de legitimação da identidade de professor pesquisador a partir da pesquisa narrativa, com um dos propósitos para evidenciar uma educação a partir e para a cidadania por meio da ciência. Além disso, houve a constatação de que a valorização da vivência e experiência de professores em formação continuada em Educação em Ciências pode auxiliar processos de (re) pensar o currículo na Amazônia.

Recebido em: 30/04/2013

Aprovado em: 17/03/2014 


\section{Referências bibliográficas}

ARROYO, M. G. Currículo, território em disputa. Petrópolis, RJ: Vozes, 2011.

AZEVEDO, J. A. (Org.). Mito da didática das ciências acerca dos motivos para incluir a natureza da ciência no ensino das ciências. Ciência e Educação, 2005.

BRASIL. Ministério da Educação. Lei de Diretrizes e Bases - LDB 9394/96.1996.

CACHAPUZ, A. (Org.). A Necessária renovação do ensino de ciências. São Paulo: Cortez, 2005.

CAPES - Coordenação de Aperfeiçoamento de Pessoal de Nivel Superior. Relatório de Avaliação 2007-2009: TRIENAL, 2010. Disponível em: <http://trienal.capes.gov.br/wp-content/uploads/2011/01/ENSINODE-CM-RELAT\%C3\%93RIO-DE-AVALIA\%C3\%87\% C3\%830 -FINAL-jan11. pdf>. Acesso em: 15 maio 2011.

CHASSOT, A. Alfabetização científica: questões e desafios para a educação. 5. ed. rev. Ijuí: Unijuí, 2011.

DELIZOICOV, D. Pesquisa em Ensino de Ciências como Ciências Humanas Aplicadas. Caderno Brasileiro de Ensino de Física, Florianópolis: UFSC, v. 21, p. 145-175, ago. 2004.

DEMO, P. Educação e Alfabetização Científica. Campinas, SP: Papirus, 2010.

FREIRE, P. Pedagogia da autonomia: saberes necessários à prática educativa. 28. ed. São Paulo: Paz e Terra, 1996.

GATTI, B. A.; BARRETTO, E. S. de S; ANDRÉ, M. E. D. de A. Políticas docentes no Brasil: um estado da arte. Brasília: UNESCO, 2011. 300 p.

GHEDIN, E. A Educação em Ciências - Área 46-Capes: Quem legitima e quem poderá legitimar essa relação complementar? Conferência 
proferida no Auditório do Centro de Estudos Superiores de Parintins Cesp da Universidade do Estado do Amazonas - UEA, 17 setembro 2010.

GONZAGA, A. M. A educação científica na formação continuada de professores no CESP-UEA: o caso do Nepecip. In: Conferência de abertura do Seminário Os percursos investigativos em educação em ciências da Amazônia no polo de Parintins. Parintins, 21 outubro 2011.

GOODSON, I. F. Currículo: teoria e história. 6. ed. Petrópolis, RJ: Vozes, 2003.

IBGE - Instituto Brasileiro de Geografia e Estatística. 2010. Disponível em: <http://www.ibge.gov.br/home/presidencia/noticias/noticia_ visualiz>. Acesso em: 11 jul. 2012.

JOSSO, M. C. A realização do ser humano como processo de transformação da consciência: ensinar, acompanhar e aprender: um mesmo desafio para uma vida em ligação. In: TRAVERSINE, C. (Org.). Trajetórias e processos de ensinar e aprender: práticas e didáticas. Porto Alegre: EDIPUCRS, 2008. p. 17-58.

LOPES, A. C. Currículo e Epistemologia. ljuí: Unijuí, 2007. 232 p.

MARTINS, I. Atas. In: ENPEC,8., 2011, Campinas. Caderno de Programação. Campinas: Enpec, dez. 2011.

MATURANA, H. R.; VARELA, F. J. A árvore do conhecimento. São Paulo: Palas Athena, 2001.

MEIRELLES FILHO, J. C. 0 Livro de ouro da Amazônia. 5. ed. rev. amp. Rio de Janeiro: Ediouro, 2006.

MEIHY, J. C. S. B.; HOLANDA, F. História oral: como fazer, como pensar. São Paulo: Contexto, 2007.

MORAES, R.; HACKMANN, B. G.; MANCUSO, R. (Org.). De Marte a Narciso: (sobre) vivências em dissertações de mestrado. Ijuí: Unijuí, 2005. 280 p. 
PACHECO, J. A. Escritos Curriculares. São Paulo: Cortez, 2005.

PRADO, G. do V. T.; SOLIGO R. (Org.). Porque escrever é fazer história: revelações, subversões, superações. Campinas, SP: Alínea, 2007.

SANDÍN ESTEBAN, M. P. Pesquisa Qualitativa em educação: fundamentos e tradições. Porto Alegre: AMGH, 2010.

SAUNIER, T. Parintins: memória dos acontecimentos históricos. Manaus: Valer/Governo do Estado do Amazonas, 2003.

SEVERINO, A. J. Expansão do ensino superior: contextos, desafios, possibilidades. In: Palestra de abertura do Fórum de Pró-Reitores de Graduação/Sudeste. Campinas, 15 fevereiro 2009.

SEVERINO, A. J.; PIMENTA, S. G. Apresentação da Coleção Docência em Formação. In: DELIZOICOV, D.; ANGOTTI, A. J.; PERNAMBUCO, M. M. Ensino de Ciências: Fundamentos e métodos. 4. ed. São Paulo: Cortez, 2011.

SILVA, T. T. Documentos de Identidade: uma introdução à teoria do currículo. 2. ed. 11. reimp. Belo Horizonte: Autêntica, 2007.

UEA - Universidade do Estado do Amazonas. Portal. 2011. Disponível em: <http:/ /www2.uea.edu.br>. Acesso em: 14 maio 2011.

UNESCO - Organização das Nações Unidas para a Educação, a Ciência e a Cultura. A ciência para o século XXI: uma nova visão e uma base de ação. Brasília: UNESCO, ABIPTI, 2013. 72 p.

ZANCAN, G. T. Educação Científica: uma prioridade nacional. São Paulo em Perspectiva, 14 maio 2000. 